\title{
Practice of Early Childhood Development Curriculum Preparation
}

\author{
Surya Prasad Adhikari \\ Lecturer \\ Central Department of Education \\ Tribhuvan University, Kathmandu, Nepal
}

\begin{abstract}
This article aimed to explore early childhood development (ECD) curriculum preparation practices. To accomplish the objective, I have collected qualitative information from ECD center through unstructured interview and discussion with the participant. This study revealed that the respondent has just Montessori basic training on pronunciation and curriculum preparation. Curriculum development center is prepares ECDC curriculums as based on the Wheeler curriculum process. However, private ECDCs prepare curriculum themselves in line with the curriculum development center. Private ECDCs have not compulsory to follow the government's curriculum. Curriculum of Curriculum Development Center focus on children's all round developments. But there is lack of spiritual development. Facilitators always start to teach/learn through the objects of the environment. Children learn more words from their mother and parents at home. Facilitators teach children by arranging the words from simple to complex. They teach correct pronunciation, structure of words and then concept.
\end{abstract}

Keywords: Curriculum, training, vocabulary, conceptualization, activity-based curriculum, experience-based curriculum

\section{Introduction}

Children from birth to eight years are considered to be in early childhood period in international practices but Nepal government has regarded as early childhood period from four to five years. This stage is important for the subsequent growth and development of child's total personality. An enriched environment during this period is desirable to bring maximum development in various aspects of the children (Adhikari, 2010). There are various forms of Early Childhood Development (ECD) programs in Nepal known by various names: Early Child Care (ECC), Early Childhood Education (ECE), Early Childhood Care and Education (ECCE), Early Childhood Care and Development (ECCD). They are run by government, communities, government organizations and non government organizations and have different forms of curriculum. Education for All (EFA) by 2015 has also put emphasis on the need for developing and running ECD programs in the country (Adhikari, 2010). Education helps human beings develop their personality and prepares them for their future life. It is considered as the cornerstone of social and economic development. Our need is not only to enroll children in ECDC but also to build the capacity 
of all ECDCs to provide appropriate education for children according to their interests. All children have the right to receive quality education without any discrimination for their overall development. It is expected that such activities will result in parents taking interest in their children's education, communities playing important roles in school development and upgrading the level of their quality day by day (Department of Education, 2010). In this context, I have discussed the children's education provided by the ECDC. Children education is related to future life skills. So, I studied ECD curriculum preparation practices to seek the answer of: Who are the curriculum makers and book writers for ECDC? Do these contents and books covers the objectives of ECDC? I interpreted finding from the Wheeler curriculum process.

Wheeler (1979) states five phases of curriculum preparation. The selection of aims, goals and objectives, the selection of learning experiences, the selection of content (subject matter), the organization and integration of learning experiences and content and evaluation. Curriculum is made from simple to complex, known to unknown way and so on. Similarly a curriculum has to fulfillment of certain objectives.

\section{Objectives}

The objective of my study is to explore the early childhood development curriculum preparation practices in Nepal.

\section{Methods}

I selected a participant who was ECD in-charge of Sunrise private school (pseudo name). This paper is based on qualitative approach of information collection and analysis for this purpose. I explored qualitative approach for this study. I purposively selected the respondent. Susmita (pseudo name), an ECD in-charge was my respondent. I develop the personal rapport and made the participant comfortable to exploring her ideas. Informally, I had an interaction with her regarding ECD, training and curriculum. To maintain the authenticity, I used my cell phone to record the information at her job place, with her consent (Starks and Trinidad, 2007).

My respondent belongs to Newar community; she speaks Nepali, Newari and English languages well and encourages other staff to speak English and Nepali in the school in order to improve their pronunciation. I have taken information in Nepali language. I also recorded the information in a diary too. I tried to incorporate the phenomenological design in the preliminary stage however the latter stage of data collection process made me shift to the design to narrative study. The analysis of the empirical data in this study is largely informed by the general inductive approach (Creswell, 2007 as cited in Khanal, 2012).

My respondent is teaching ECD children. She believes that ECD stage is known as preprimary level. She had been working for eight years in Sunrise School.

I prepared some 'basic themes' from the data elicited from the recorded narrative and the diary writing. From the commonalities of the basic themes, I prepared 'organizing themes', and then I came to the 'global themes' (Stirling, 2001). The analysis is carried out through multiple readings and interpretations of the raw data, the inductive component (Thomus, 2006). The 
analysis is carried out through multiple readings and interpretations of the raw data, the inductive component (Khanal, 2012). I tried to make different "themes" from the information or data which is related to my research objective. The transcripts were read several times to identify themes and categories (ibid).

\section{Results and Discussion}

The results are discussed under the following headings:

\section{Training and education is the key}

Training often focuses on the immediate period to help fix any current deficits in employee's skills while development focuses in the long term to help employee prepare for future work demands. It refers to learning opportunity which does not have to be limited to improving employee's performance on their current jobs. Training is a learning experience in that it seeks a relatively permanent change in an individual that will improve his/her ability to perform on the job (DeCenzo and Robbins, 2005). I asked questions to explore training experience of the participant.

She has got eight years experience in that school. Eight years ago she worked at Hill-Town International School, Kirtipur. She worked in pre-primary school in Bungmati before. It means altogether she worked 17 years in the same level. Susmita said:

I have been teaching for seventeen years at pre primary level. I am feeling very happy with my job, because I got this job when I was looking for. I am not feeling any bore while teaching/learning to the children. School environment was also the same as home, because I have small sisters at home. Slowly I became a mother and engaged with my children. So, I became very much engaged in my family and job.

Here, she enjoyed and spent time with the ECD children. She did not feel bored because of her interest was on teaching. She has got homely environment in the school. She grew up by playing with her junior sisters and acculturates them. This can be related to the practice which we have in the Nepalese society where most of the elder sister duty is to care the younger sister/brother at home. This situation made her excitement and let the situation more explored. She got married and had a child. This situation made her very easy to behave with the children shaping the professional environment between home and school. She has taken training on ECD from Hilltown International school which was her first opportunity to participate in the training. (Kafle \& Aryal, 2002 as cited in Adhikari, 2010) defined training as the process of behavior shaping as training makes the teacher perfect in teaching. Training for teacher is crucial for the development of teaching competency. Susmita said:

Training was given and managed by the administration of Valley International School, which was compulsory for primary level teachers. That was my first experience of training about the ECD. My second training was related to the practiced of five sensory organs while teaching/learning practices. Similarly teachers/ facilitators must give more emphasis on concrete things then abstract ideas. 
The training was managed by the school administration of Valley International School, which was compulsory for primary level teachers and below. The name of that training was "Primary teachers training with Montessori techniques". She was given the training based on Montessori technique by the ECD trainer.

The training included different aspects maximizing the practices of sense organs. She had practiced the five sense organs that make the student active. The first priority must be given to "concrete" then "abstract". The training focused learning from the environment by touchable, visible and hearable. It was more focused on the semiotics mode of training. It helped her to shape learning environment effective as priority should be given to the environment. Curriculum is said to be the textbook not for the syllabus in many cases, textbook is perceived as curriculum. After the training, she felt the necessity of curriculum for the ECD. School administration was asked about the curriculum for the ECD. After that the training participants realized about the curriculum for the ECD. All the books which were available in the market for the ECD were considered as curriculum. But her opinion, only textbooks are not syllabus. A textbook is a medium which helps to implement the curriculum. She had not received any training about the curriculum of ECD. But she did one year B. Ed. from T.U. She was irregular student though she knew about the textbook and curriculum through self-study. Regular children may learn content, teacher imitation and behave well more than irregular children in ECDC.

Curriculum preparation and teaching/learning training are not given as Wheeler curriculum process. Objectives of each private ECDC are somehow different than curriculum development center. Parents were busy in their job and the objective of ECDC was only engaging the children. Likewise, teaching/learning contents are not completely focusing for learning experiences. Similarly, organization of content and evaluation system is not as mentioned by Wheeler curriculum process. Teaching/ learning objectives, learning experiences, contents organization and evaluation system are prepared by each ECDC. The ECDC try to achieve their objectives only, they do not completely follow then ational objectives. Most of the training packages only focus on preparation of teaching/learning materials and proper use, care of children, sanitation and so on.

\section{Experience-based curriculum}

The experience may comprise earlier events in the life of the learner, current life events, or those arising from the learner's participation in activities implemented by teachers and facilitators. A key element of experience based curriculum is that learners analyze their experience by reflecting, evaluating and reconstructing it in order to draw meaning from it in the light of prior experience. The review of their experience may lead to further action (Andresen, Boud \& Cohen, 1995). As Susmita knew the government of Nepal prepared the curriculum for ECD. But, she did not know the right authority to prepare curriculum. Susmita expressed about the preparation of ECD curriculum in the following way:

I was unknown about the curriculum preparation. But I saw the curriculum of ECD in the book form, I was teaching/learning at private school. Private schools are not compelled to follow the government curriculum. We did not have curriculum as in 
written form but we were teaching mostly based on our experience and we know that priority should be given to overall development of children.

As she saw, the curriculum that was in a book form. She knew that the private schools may also follow the government curriculum. Curriculum is prepared by the Curriculum Development Centre for the school level. These curriculums are compulsorily implemented by the government in the government and private schools.

The school authority had appointed the ECD facilitators for enhancing the overall development of the children through teaching/learning activities. Teaching/learning activities were based on textbooks. Facilitators did not prepare any syllabus for the ECD. They were found more conscious about all round development of the ECD children. They shared the different ideas, experiences and activities through the teaching/learning processes. Susmita again said:

There are several ECD books in the market for the curriculum of ECD. But I am unknown and confused about the books written by educationists and educational psychologists. These books cover the ECD curriculum.

There are some books in the market written by different writers. Among them all may not be excellent. They may not cover all aspecst of development because the writers might not be psychologists and educationists. Syllabus is not sufficient because it does not cover all round development such as physical, mental, social and emotional. Feeling and physical development are found to be missing. There are fewer practices for the physical development of the children. There are two types of physical development; "gross motor" and "fine motor". These are not mentioned in the curriculum. Children limit themselves in viewing the ideas and memorization often called as "parrot learning".

There are different types of teaching/learning approaches; Montessori, thematic, conceptual. The founder of Montessori methods is Maria Montessori. But my respondent did not know about the founder of thematic and conceptual approaches. All of these approaches are different from each other. Montessori method and thematic approach are different. Conceptual approach is known as learning through the environment. We must know about all round development of children while preparing the curriculum for the CED. There is an order/sequence of the learning skills/ knowledge. Regarding the ECD curriculum Susmita states:

Language development, social development, physical development, emotional development, and cognitive developments are seen in DCDC. Spiritual development is not found in the ECDC but comes after complete ECDC. Adaptation in the new environment is very difficult because of language problem. Children in ECD are from different mother tongue group. Facilitators must know the children's first language then $\mathrm{s} /$ he learns slowly the second language it helps to develop more vocabulary.

Bernstein asserts language 'is considered one of the most important means of initiating, synthesizing, and reinforcing ways of thinking, feeling and behavior which are functionally 
related to the children. Language is a powerful tool for academic success and social mobility (Khanal, 2017). Depending upon the individuals' home and immediate school/ECDC and social environment, they may acquire two types of language codes to varying degrees- restricted and elaborated code (Bernstein, 1971 as cited in Khanal, 2017). Susmita expressed her views:

It is more difficult to adjust the children in ECDC because of the food habit, living with male/female, living with friends or single, toilet, toys. But all these activities help to develop more "vocabulary" and fast "adjustment" in the ECDC.

Cherryholmes (1988) also agrees on the reality formed by the power of language wording, and inter-textual relationships. We must manage homely environment in the ECDC for spending children's time. All the facilitators should always actively participate and attract the children by their good manner. After adjustment of the children in ECD facilitators manage the learning environment by different activities.

Curriculum preparation practices are differ. Curriculum Development Center practices curriculum following the Wheeler curriculum process. However, private ECDC prepare curriculum themselves, somehow different from CDC. Private ECDC has no compulsion to follow the CDC curriculum. But they are teaching curriculum on their experience. Private ECDC's curriculum may not cover all the of learning areas mentioned in Wheeler curriculum process. Children's all round development except spiritual developmentia focused by CDC curriculum. Language problem is seen because of language diversity. Children are developing more vocabulary, good habits from the ECDC.

\section{Activity-based experience learning}

Susmita has received training on English pronunciation from British council for about six months. The training was focused on English pronunciation and curriculum for ECDC/schools children. German and Italian young ladies were the trainers and they focused on blending pronunciation and curriculum. Susmita expressed that:

Home is the first school of children. Children learn simple letters, words and sentences from their home. Schools/ECDCs guide to the children by listening, speaking, reading and writing correctly. Frequently we make them practise in schools/ECDCs then gradually children learn many more.

House is the first school for the children and parents are the first teachers of children. Children learn many more words from the house but ECDC facilitators arrange them simple to complex, for writing form, proper pronunciation, structure of the letters words, concept, construct and personalize them properly. Karlinger (2012) stated that construct is a concept which add meaning of having been deliberately and consciously invented or adopted for a special scientific purpose. Children can easily learn through their own experiences, what they learn at home. It is more effective to learn it means go through "concrete" to "abstract". 
Main focus should be given to touchable, visible and hear able entities. These make the learning environment effective and understandable, and to conceptualize knowledge. Children are from different experiences so facilitators have to address their knowledge as Susmita said:

If we talk in the class about the "Taj Mahal" to our small children, they do not understood, surely that becomes value less. So, that we should always use of nearby objects and simple language. Teachers/facilitators always concern about the capacity of the children then use simple language and care about the interest of the children. Initially, teachers/ facilitators should always be careful to teach/learn simple and familiar words. That increases the children's interest to learn. So, the teacher should start teaching through the objects lying around them.

If we describe unseen object that may be valueless. Facilitators need to use very close and familiar words which are available for the beginners. They have to teach the students by introducing classroom objects then the ground objects of the environment. Children learn different activities from the ECDC. Parents cannot manage all the materials like ECDC however can relate the available in our kitchen and bedroom as a form of home sciences. The bed room does not simply contain a bed but incorporates several objects such as, doors, windows, cupboard, drawers and furniture which are the objects to teach. These are the common materials which are available at school and home, through these common materials children can learn easily. That is why common materials should be given the first priority to learning for the children. (Bourdieu,1986 as cited in Underwood, 2011) assets that cultural capital includes all non financial social assets such as languages, vocabularies, communication pattern, education dress or physical appearance that affect the educational success and social mobility of children. School success by 'the amount and type of cultural capital inherited from the family background rather than by measures of individual talent or achievement'. Parents do not have any more expectation than their children learn the words with correct pronunciation for the first stage. So the curriculum must address the repeated words at home and ECDC.

In Nepalese context children from 3-5 years are eligible to admit at ECDC. Parents are being more busy for spending quality of life. So, they do not have sufficient time to take care their children properly at home. As a result, they want to keep their children even before the age of 3 years. ECDC facilitators must have various kinds of skills like; life skills, art and craft, singing and song, dancing, listening, speaking, reading, writing, planning, organizing, coordinating, programming, pronunciation, skills of different games, preparation of curriculum, languages, teaching and learning skills. We should encourage children and staff to activate their five sense organs. There are various types of trainings among them Montessori is the most popular. Most of the ECDC facilitators have basic Montessori training. Facilitators can use thematic and conceptual approaches for teaching and learning.

Facilitators were familiar about the ECDC curriculum, however, they do not know the details. Facilitators were often found in confusion about the available books of ECD which may or may not fulfill the curriculum goals but they are less aware about the scope and sequence and 
books which are not written by the specialist, psychologists and educationists. They are always conscious about all round development of children. Market books focus on sensory organs but not on physical and feeling development. The children from different mother tongue are feeling more difficulty to adjust in the ECDC.

All of the children learn more words from their parents and other elder members at home. There are many more objects in their house and around the environment. Facilitators can explore children by arranging these words by simple to complex. Similarly, they can teach children by correct pronunciation, structure of words, writing the words then concept and construct these words in their mind.

Children learn letters, words and sentences at their home. Frequently facilitators gradually teach the children correctly pronounce and write. Facilitators should always teach the nearby familiar objects and use common simple language. Facilitators always start to teach through the objects of the environment and children experience as Wheeler learning experiences.

\section{Implication}

BPEP I (1991-1998) has launched Sishu Kakshas (pre-school classes) attached with the primary school. BPEP II (1999-2004) under the Ministry of Education and Sports had initiated to operate Shishu Vikass Kendra for the children aged 3-5 years through the active participation of the local community. Education for All (2015) has also put emphasis on the need for developing and running ECD programs in the country. Education structure is basic school education and secondary school education. Basic school education is from one class to eight class. Before one class children learn basic life skills activities. Each community school is providing one year education before one class. Most of the private ECDs or schools are providing child care, nursery, LKG, UKG education of one to three years.

ECDCs are the parent's targets for their children's physical, mental, social and emotional development and care. The priority of parents is unidentified for their children; either in learning, time pass, care or else what.

\section{Conclusion}

From the above discussion children from 3-5 years are eligible for ECDC in Nepal. Nowadays parents have to keep themselves busy to meet the quality of life. They do not have time to care their children properly at home. Because of that reason, parents want to enroll their children even before the age of 3 years. ECDC facilitators must have various kinds of skills such as life skills, art and craft, singing, dancing, listening, speaking, reading, writing, planning, organizing, coordinating, programming, pronunciation, basic skills of some games, preparation of curriculum, languages teaching and learning skills. We should encourage children and staff to activate their five sense organs. There are various types of ECD trainings among them Montessori is the most popular. Most of the ECDC facilitators have basic Montessori training. Facilitators can use thematic and conceptual approaches for teaching the classroom. 
Facilitators have knowledge of the curriculum for ECD, but they minutely do not know what is there in details. Facilitators have a lot of confusions about the ECD books available in the market. They do not know either these books fulfill the curriculum goals or not, or these books are written by the specialist, psychologist and educationist or not. Facilitators are always conscious about all round development of children. Market books focus on sensory organs but not on physical and emotional development. Children have language problem. The children from different mother tongue feel more difficulty to adjust in the ECDC.

The children learn more words from their parents and other elder members at home. There are many more objects in their house and outside the house or environment. Facilitators help children learn the words arranging them from simple to complex. Similarly they can make learn the correct pronunciation, structure of words, creating concept and constructing these words in their mind.

\section{References}

Adhikari, S. P. (2010). Professional motivation of ECD facilitators. (Unpublished master thesis), Department of Educational Planning and Management, Faculty of Education, Tribhuvan University, Kirtipur.

Andresen, L., Boud, D. \& Cohen, R. (1995). Experience-based learning in Understanding adult education and training (2nd ed.). Foley (Editors). Sydney: Allen \&Unwin

Cherryholms, C. H. (1988). "Power and criticism” Poststructural investigation in education; Retrieved from www.questia.com

DeCenzo, D. A. and Robbins, S. P. (2005). Fundamental of human resource management. New Delhi: John Wiley and Sons.

Department of Education (2005). Early childhood development handbook curriculum. Bhaktpur: Department of Education

Department of Education (2010). National framework of child-friendly school for quality education. Bhaktapur: Department of Education.

Karlinger, F. N. (2012). Foundations of behavioral research. Delhi: Surjeet Publication.

Khanal, P. (2012). Policy as practice of power: an analysis of the policy to decentralize school education in Nepal. (An unpublished Doctorial dissertation), Centerbury Christ Church University.

Khanal, P. (2017). Pedagogy, culture \& societyfalling prey to the dominant culture? Demystifying symbolic violence against ethnic minority students in Nepal. Retrieved from http:// www.tandfonline.com

MOES (2003). Education for all 2015. Kathmandu: Auther

MOES (2005). National curriculum framework for school education (Pre-primary-12) in Nepal. Bhaktpur: Ministry of education and sports. 
Starks, H. \& Trinidad, S. (2008). Choose your method: A comparison of phenomenology, discourse analysis, and grounded theory in Qualitative health research 17(10):137280 DOI: $10.1177 / 1049732307307031$

Starlin, J. A. (2001). Qualitative research, thematic networks: An analytic tool for qualitative research. (3): 385 - 405. London: Sage publications.

Thomas, D. R. (2006). American of evaluation. A general inductive approach for analyzing qualitative evaluation data 27 (2): 239 PUB American evaluation association.

Tribhuvan University (2071). Semester nirdesika. Kathmandu: Tribhuvan University.

Underwood, J. J. (2011). The role of cultural capital and parental involvement in educational achievement and implications for public policy. (An unpublished master degree thesis). Faculty of the department of sociology, East Carolina University.

Wheeler, D. K. (1979). Curriculum process. London: Hodder and Stoughton. 